\title{
Using indicator species to detect high quality habitats in an East African forest biodiversity hotspot
}

\author{
Jan Christian Habel ${ }^{1,2} \cdot$ Camilo Zamora ${ }^{2}$. Dennis Rödder ${ }^{3} \cdot$ Mike Teucher $^{4}$. \\ Ivon Cuadros-Casanova ${ }^{2,5} \cdot$ Christina Fischer $^{6,7}$
}

Received: 27 May 2019 / Revised: 21 December 2020 / Accepted: 20 January 2021 /

Published online: 13 February 2021

(c) The Author(s) 2021

\begin{abstract}
Species demanding specific habitat requirements suffer, particularly under environmental changes. The smallest owl of Africa, the Sokoke Scops Owl (Otus ireneae), occurs exclusively in East African coastal forests. To understand the movement behaviour and habitat demands of $O$. ireneae, we combined data from radio-tracking and remote sensing to calculate Species Distribution Models across the Arabuko Sokoke forest in southern Kenya. Based on these data, we estimated the local population size and projected the distribution of current suitable habitats. We found that the species occurs only in Cynometra woodland with large old trees and dense vegetation. Based on home range sizes and the distribution of suitable forest habitats, the local population size was estimated at $<400$ pairs. Ongoing selective logging of hard-wood trees and the production of charcoal are reducing habitat quality of which will reduce the low numbers of $O$. ireneae, and of other specialist forest species, even further. Due to their close connection with intact Cynometra forest, $O$. ireneae is an excellent indicator of intact forest remnants. In addition, this species is a suitable flagship for the promotion and conservation of the last remaining coastal forests of East Africa.
\end{abstract}

Keywords Cynometra forest $\cdot$ Habitat quality $\cdot$ Otus ireneae $\cdot$ Population size $\cdot$ Movement behaviour $\cdot$ Radio-tracking $\cdot$ Roosting trees $\cdot$ Species distribution model $\cdot$ Carrying capacity

\section{Introduction}

One of the main drivers of global biodiversity decline is habitat destruction (Maxwell et al. 2016) with many tropical ecosystems being transformed into agricultural land for largescale cash-crop production and subsistence agriculture (Geist and Lambin 2002). Not only

Communicated by Stephen Garnett.

This article belongs to the Topical Collection: Forest and plantation biodiversity.

Jan Christian Habel

Janchristian.habel@sbg.ac.at

Extended author information available on the last page of the article 
are natural habitats, species and local populations being lost (Cincotta et al. 2000; Miles et al. 2016), but the quality of remaining habitat is deteriorating, especially for taxa with specific habitat demands (Carignan and Villard 2002). Even forests with a closed tree canopy are being compromised by selective logging and the exploitation of natural resources, such as the collection of dead wood and the poaching of animals (Gatti et al. 2015).

Various strategies have been proposed to identify and manage endangered ecosystems and species. One strategy is to use indicator species to identify intact remnants of endangered ecosystems, and to evaluate their ecological integrity (Carignan and Villard 2002). Thus, surrogate species which represent a specific habitat type and which are highly sensitive to changes of habitat quality may help to identify the best remaining remnants of an ecosystem (Githiru et al. 2007; Murphy et al. 2011; Banks et al. 2014). The explanatory power of indicator species is high for two reasons: first, they can indicate it is likely other sensitive species will inhabit the same ecosystem, and second, because indicator taxa immediately respond to environmental changes, such as the deterioration of habitat quality (Simberloff 1998).

The forests of tropical Africa suffer the highest rates of deforestation in the world (Hansen et al. 2013; Achard et al. 2014), with 93.0\% of natural forests of East Africa having been destroyed (Aleman et al. 2018). The quality of small and patchy forest remnants is also decreasing, primarily because of selective hardwood logging, firewood collection, charcoal production, and various infrastructure projects (Gordon and Ayiemba 2003; Habel et al. 2017). Selective logging, for instance, affects tree species composition and changes habitat structure including canopy height and vegetation density, and reduces the availability of many resources needed by specialist species (Gatti et al. 2015).

The Sokoke Scopes Owl (Otus ireneae) occurs exclusively in Cynometra woodland, which makes up a fraction of the dry coastal forest in East Africa (Virani 1994; Fanshawe 1995; Cuadros-Casanova et al. 2018). Apart from a few very small isolated populations elsewhere (Evans 1997; Virani 2000; Virani et al. 2010), almost the entire population of $O$. ireneae is restricted to the Arabuko Sokoke forest, located north-east of Mombasa in southern Kenya (Virani 1994; BirdLife International 2018). However, the Arabuko Sokoke forest has been subject to the illegal logging of large Brachylaena and Cynometra trees, which has changed the forest's structure (Fanshawe 1995; Muriithi and Kenyon 2002). Due to this habitat destruction and the declining habitat quality, the population of $O$. ireneae has declined considerably during the last two decades (Virani 2000; Virani et al. 2010).

In this study, we radio-tracked ten $O$. ireneae individuals in order to analyse the species movement behaviour, and to estimate home ranges. We then combined the radio-tracking data with satellite images in order to calculate Species Distribution Models (SDMs). Based on the habitat requirements derived from the SDMs, we projected the extent of the potentially suitable $O$. ireneae habitat and calculated the carrying capacity of the forest (Fig. 1).

\section{Methods}

\section{Study area}

East African dry coastal forest consists of three forest types: Cynometra forest (further subdivided into Cynometra thicket and Cynometra woodland), Brachystegia forest, and Mixed forest (formerly named Afzelia forest or Hymenaea-Manilkara forest; Muriithi and Kenyon 2002). The Arabuko Sokoke forest in southern Kenya is the largest remaining dry coastal 
forest block in East Africa, with a total extent of 41,600 ha (Wass 1995; Bennun et al. 1996). Considered an Important Bird Area (IBA), the Arabuko Sokoke forest is listed as the second most important site for bird conservation in Africa due to the high number of bird species, including many forest endemics (Collar and Stuart 1988; Bennun and Njoroge 1999).

\section{Radio-tracking}

We performed radio-tracking of $O$. ireneae during the transitions between the Wet and Dry Seasons, in July and August 2016-2017. Ten individual owls (all adults, gender could not be determined) were caught with mist-nets set around their roosting trees. We banded each owl and measured their head, wing, tarsus, and body weight. We then attached a radio transmitter (Pip Ag376; Biotrack Ltd, Wareham, UK, with a weight of $1.5 \mathrm{~g}$ ) as a backpack with a "wing-loop" harness made of natural rubber to each of the owls. The weight of the radio transmitter was less than $2 \%$ of the total body weight (mean $50 \pm 1.7 \mathrm{~g}$ ), well below the commonly used threshold (4-5\% of body weight; see Kenward 2001).

We conducted radio-tracking with hand-held receivers (AR8200-MK3, AOR Inc. USA) and four-element Yagi antennas. Two observers simultaneously took bearings of tagged owls every 20 min from 6 pm until 6 am using a compass, recording their own position with a hand-held GPS device (Garmin GPSmap 64x). The two observers maintained positions of at least $300 \mathrm{~m}$ distant from each other. Data collection was split into two $6 \mathrm{~h}$ periods (6 pm till midnight; midnight till 6 am). During the early morning, the tagged owls were followed in order to locate their roosting trees. The exact position of each owl was calculated by triangulating the bearings of both observers. Positions calculated for the first day after tagging were excluded due the potential for atypical movement behaviour. Positions with distances $>1000 \mathrm{~m}$ were excluded from the data set as the transmitters had a maximum range of $1000 \mathrm{~m}$. The roosting trees of each individual were identified, and subsequently geographically determined.

\section{Home range estimation}

Home range sizes of $O$. ireneae individuals were estimated using Minimum Convex Polygons (MCP) and Autocorrelated Kernel Density Estimation (AKDE) for 95\% (transitional area) and 50\% levels (core area). The MCP home range sizes enabled us to compare our data with the results of previous studies (e.g. Virani 1994). The AKDE method allowed for the more precise estimate of particularly small home range sizes, compared with conventional Kernel density estimators, as it corrects estimates for temporal autocorrelation (here, 20 min intervals; Noonan et al. 2019). The AKDE home range size were calculated by fitting continuous-time movement models (ctmm), which were visually inspected in order to assess the autocorrelation structure of the movement data and selected using the Akaike Information Criterion, corrected for small sample size (AICc). From the best model, the AKDE utilisation distribution and home range sizes were calculated (Fleming and Calabrese 2017). Incremental area analysis was then conducted in order to determine whether home range size reached an asymptote, thus indicating that the number of locations was sufficient. In this study, home range estimates reached an asymptote after 180 to 200 relocations. The analyses were performed using the "Animove-Triangulation" package in QGIS v. 2.0.1; MCP home range estimators were calculated with the R package "adehabitatHR" 
(Calenge 2006); and AKDE estimators were generated with the R package "ctmm" (Calabrese et al. 2016).

\section{Species distribution model}

SDMs were created on the basis of calculated positions (fixes) obtained from radio-tracking and the following environmental variables: tree cover, tree height, Normalized Difference Vegetation Index (NDVI), spectral information from blue, Mid-Infrared (MIR), NearInfrared (NIR) bands, and vegetation type. These environmental variables were selected following observations of the species' habitat characteristics and behaviour (see CuadrosCasanova et al. 2018) and are based on land cover data derived from satellite imagery (sources detailed in Table 1). These were resampled to a resolution of $30 \mathrm{~m}$ using a nearest neighbour approach (package "raster", Cran R, Hijmans 2016). Maximum Entropy modelling (MaxEnt v. 3.4.1) was employed to perform SDM (Phillips et al. 2006) using a Jackknife test in order to measure variable importance in the model development. Model performance was evaluated by examining the area under the receiver operating characteristic curve (AUC), where values of $0.5-0.7$ were considered low and thus represented poor model performance, whereas values of $0.7-0.9$ were considered moderate, and values $>0.9$ represented excellent model performance (Phillips et al. 2006). Based on the assumptions that the home ranges of individuals, i.e. pairs, do not overlap, and that $O$. ireneae primarily occurs as pairs (i.e. two individuals per home range), the following total pair numbers were estimated by combining the home range estimate per individual (E/I) with the potentially suitable habitat size (SHS). Following a bootstrap approach, 20\% of the fixes were randomly selected as test records, while the remaining $80 \%$ were used to train the model. This procedure was repeated ten times and averaged over all repetitions. The lowest ten percentile training omission threshold accounting for potential spatial triangulation errors was selected as the presence-absence threshold. All computations were performed in QGIS v. 2.0.1, and MaxEnt v. 3.4.0 (Phillips et al. 2006). Finally, the carrying capacity for $O$. ireneae was estimated based on the spatial expansion of potentially suitable habitats obtained from SDMs, and the mean home range size of the AKDE calculations.

\section{Results}

Ten $O$. ireneae individuals were radio-tracked for, on average, $23.5 \pm 1.0$ nights (ranging from 20 to 25 nights). The $O$. ireneae home range size was calculated by MCP95 at $14.2 \pm 1.9$ ha, and MCP50 at $2.8 \pm 0.3$ ha. The transitional area calculated by AKDE95 was $18.9 \pm 2.2$ ha, and the core area calculated by AKDE50 was $3.5 \pm 0.3$ ha (Table 2). The home ranges of radio-tracked owls did not overlap, or did so only marginally.

MaxEnt models provided reasonable predictive power with $\mathrm{AUC}_{\text {test }}$ values of 0.77-0.87. The area of suitable habitat was estimated at 5283 ha. Most of the projected suitable habitat distribution was fragmented Cynometra woodland with largest patches in the northwestern and south-eastern parts of the Arabuko Sokoke forest (Fig. 2). Estimates of the relative contributions of the environmental variables showed that tree height, NDVI, and $N I R$ explained the most variation (percentages contributed by all variables are presented in Table 3). The Jackknife test indicated the most pronounced drop in explanative power when omitting tree height. Computing SDMs based on the single variables NDVI and MIR had 


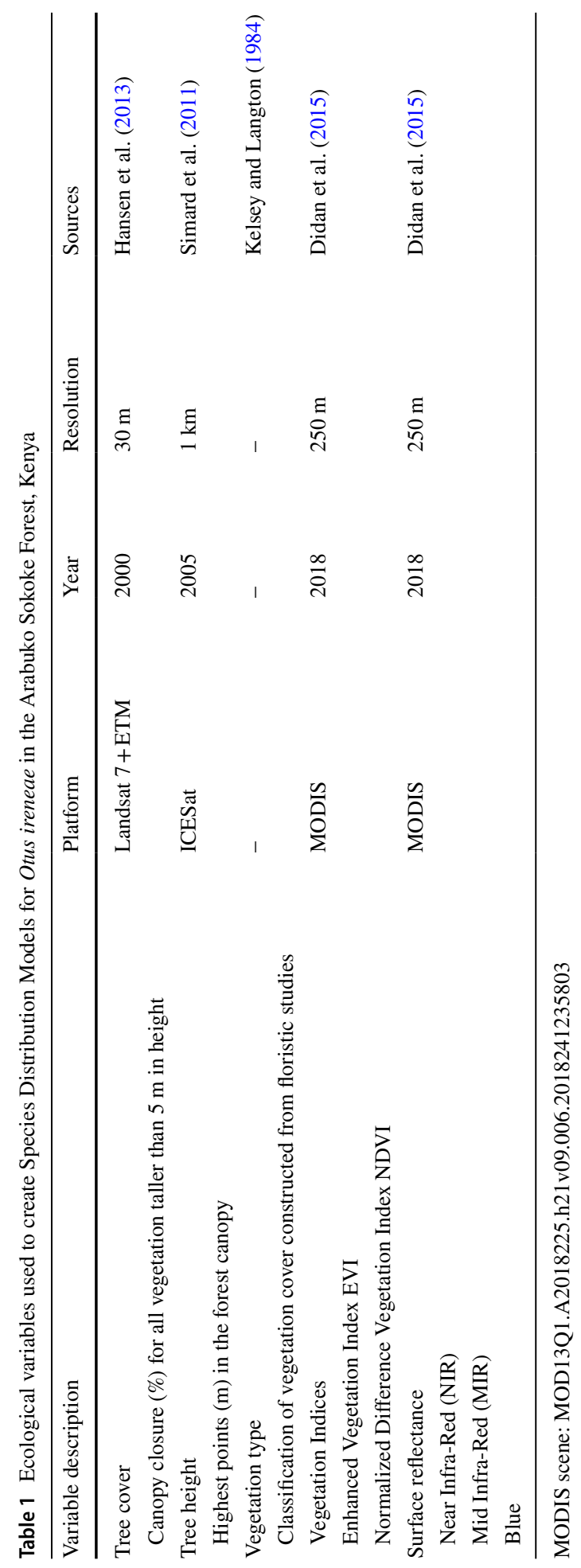




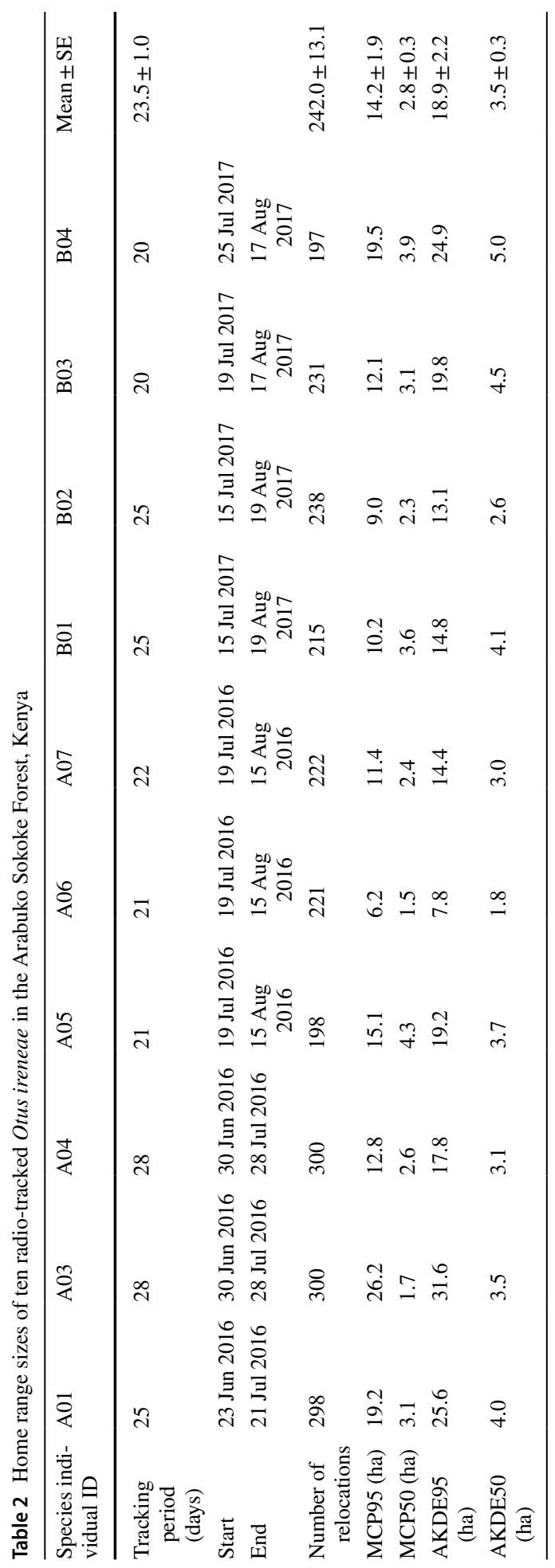



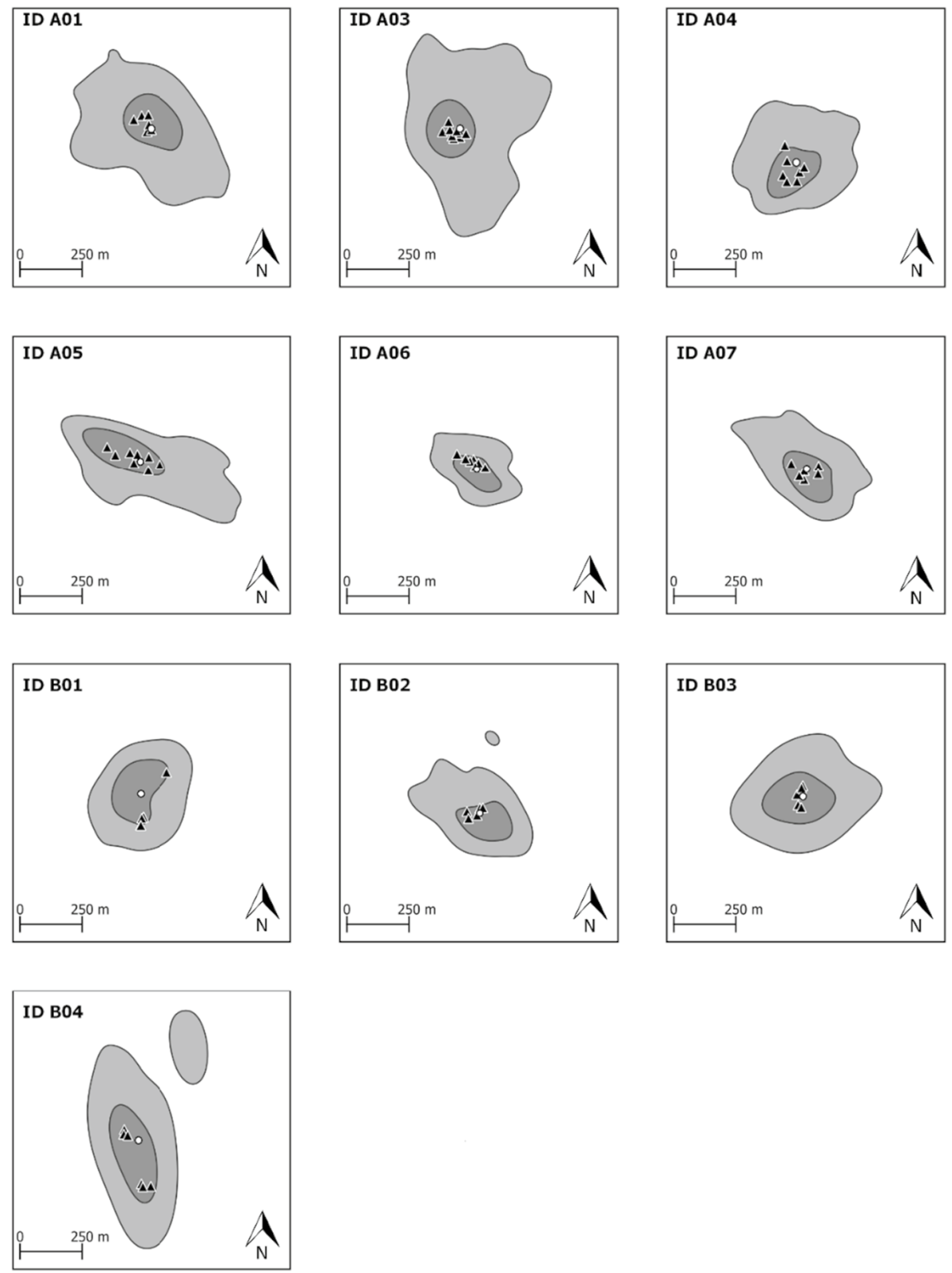

Fig. 1 Home ranges of ten radio-tracked Otus ireneae individuals in the Arabuko Sokoke Forest, Kenya. Light grey: transitional area (AKDE95); dark grey: core area (AKDE50); black triangles: roosting trees, white dots: mean centre

the highest explanatory power, whereas vegetation type had the lowest explanatory power (Table 3). Only a fraction of the total Cynometra forest was indicated as being potentially suitable for O. ireneae, with 7613 ha $(32.2 \%)$ being suitable based on MCP95, 7361 ha (31.3\%) based on AKDE95, and 5433 ha (23.1\%) being suitable based on AKDE50. 

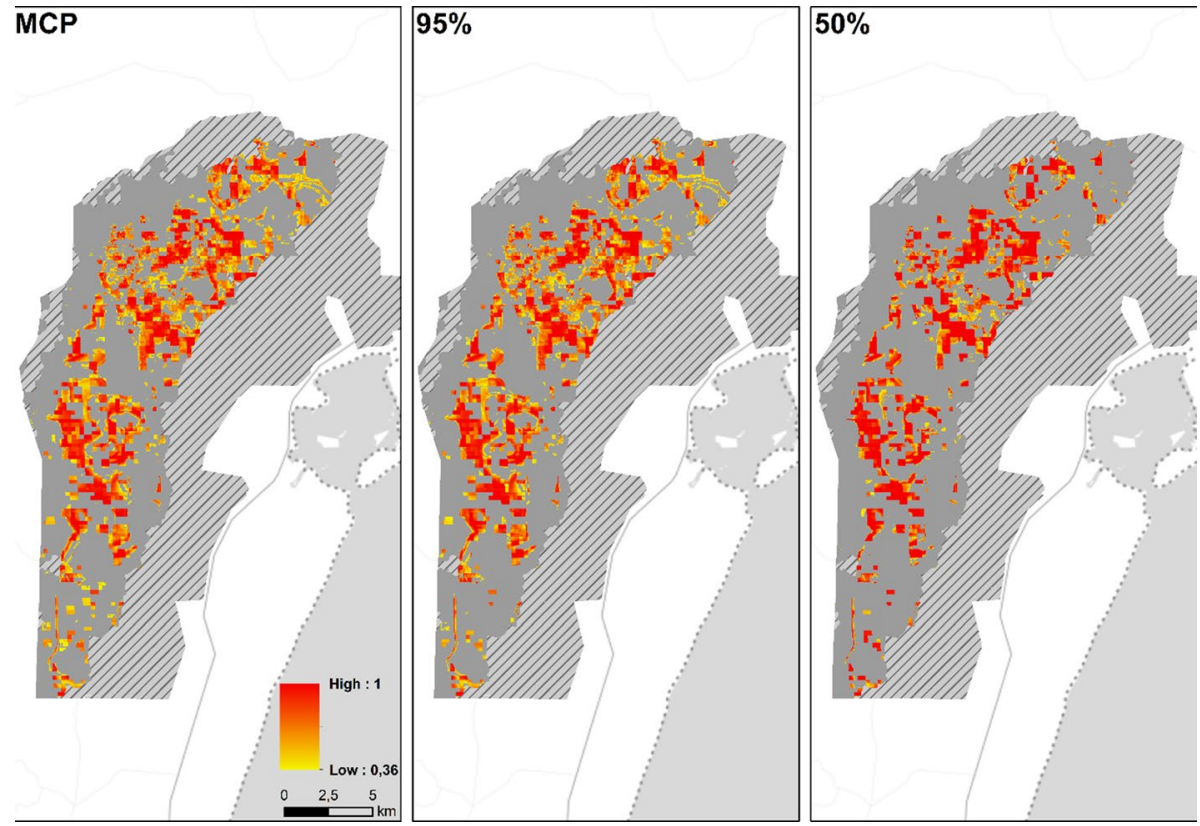

Fig. 2 Habitat suitability map for Otus ireneae in the Arabuko Sokoke Forest, Kenya showing the probability of occurrence of the species, based on a MaxEnt model, on a scale from low probability (yellow) to high probability (red) with the three different maps representing SDMs trained with all fixes within the MCP95 per specimen (left), with fixes within the AKDE95 (middle), and fixes within the AKDE50 (right). Unsuitable areas are marked in hatched grey, darker grey areas represent Cynometra forest, white non-forested habitat and light grey areas the Indian Ocean, bounded by a dotted line

Finally, the $O$. ireneae carrying capacity of the entire Arabuko Sokoke forest was estimated. The total estimate was 387 pairs across the Arabuko Sokoke forest based on AKDE95, 19 ha E/I and 7361 ha SHS and 544 pairs based on MCP95, 14 ha E/I and 7613 ha SHS.

\section{Discussion}

\section{Home range and population size}

The population of $O$. ireneae in the Arabuko Sokoke forest occurs at much higher densities than the only other population for which density measures exist-the Usambara Mountains where there were 1.5-4.0 pairs $/ \mathrm{km}^{2}$ over an area of 9700 ha (Evans 1997). Nevertheless, the average home range size we obtained for tracked $O$. ireneae based on AKDE95 $(18.9 \pm 2.2 \mathrm{ha}$ ), which is thought to be particularly accurate (Noonan et al. 2019), continue a long-standing increasing trend: Home range size estimates have gone from 12.5 to 14.3 ha/pair in 1973-1979 (Britton and Zimmerman 1979) and 1984 (Kelsey and Langton 1984) to 14.9 ha/pair in 1994 (Virani 1994), 16.1 ha/pair in 2003 and 17.5 ha/pair in 2008 (Virani et al. 2010). The increase in home range size is reflected in the estimate of the 
Table 3 Summary of SDM results depicted from Species Distribution Models

\begin{tabular}{|c|c|c|c|}
\hline Model evaluation & МСР95 & AKDE95 & AKDE50 \\
\hline Training AUC & 0.75 & 0.77 & 0.87 \\
\hline Test AUC & 0.75 & 0.76 & 0.86 \\
\hline \multicolumn{4}{|l|}{ Variable contribution } \\
\hline Canopy Cover & 8.67 & 6.918 & 6.03 \\
\hline Vegetation Type & 0.13 & 0.10 & 0.02 \\
\hline EVI & 14.90 & 17.53 & 10.67 \\
\hline MIR & 12.31 & 10.98 & 8.42 \\
\hline NDVI & 9.14 & 9.35 & 16.74 \\
\hline NIR & 13.31 & 11.80 & 11.35 \\
\hline Blue & 5.99 & 6.28 & 6.30 \\
\hline Tree Height & 35.55 & 37.05 & 40.48 \\
\hline \multicolumn{4}{|l|}{ AUC without... } \\
\hline Canopy Cover & 0.75 & 0.76 & 0.86 \\
\hline Vegetation Type & 0.75 & 0.76 & 0.86 \\
\hline EVI & 0.74 & 0.75 & 0.85 \\
\hline MIR & 0.75 & 0.76 & 0.86 \\
\hline NDVI & 0.74 & 0.76 & 0.86 \\
\hline NIR & 0.75 & 0.76 & 0.86 \\
\hline Blue & 0.74 & 0.76 & 0.86 \\
\hline Tree Height & 0.72 & 0.73 & 0.82 \\
\hline \multicolumn{4}{|l|}{ AUC with only... } \\
\hline Canopy Cover & 0.55 & 0.56 & 0.59 \\
\hline Vegetation Type & 0.50 & 0.50 & 0.50 \\
\hline EVI & 0.62 & 0.62 & 0.69 \\
\hline MIR & 0.57 & 0.57 & 0.62 \\
\hline NDVI & 0.71 & 0.72 & 0.78 \\
\hline NIR & 0.67 & 0.67 & 0.74 \\
\hline Blue & 0.61 & 0.62 & 0.67 \\
\hline Tree Height & 0.68 & 0.68 & 0.75 \\
\hline \multicolumn{4}{|l|}{ Threshold } \\
\hline $\begin{array}{l}10 \% \text { training presence } \\
\text { logistic threshold }\end{array}$ & 0.37 & 0.36 & 0.40 \\
\hline
\end{tabular}

Given are details on variable contributions with respective AUC values, for MCP95, AKDE95 and AKDE50

population size: 1025 pairs in 2000 (Virani 2000), 800 pairs in 2008 (Virani et al. 2010) and 387-544 pairs in our study. While such differences in population densities and sizes could be a result of differences in data collection techniques, data quality or in the algorithms applied to estimate home ranges, they could also be caused by a decline in habitat quality. 


\section{Habitat quality}

Increasing home range sizes may be a response to decreasing habitat quality with reduced resources (e.g. food). Wiktander et al. (2001) showed that home range sizes decrease when resources become scarce (e.g. during the dry season). Such environmental changes may also be due to anthropogenic habitat deterioration, which influences habitat structures, species communities, and the availability of resources. This, subsequently impacts individual behaviour (Villard et al. 1999; Banks et al. 2012, 2017; Ndang'ang'a et al. 2013). Previous studies have shown that birds living in degraded environments need to cover larger areas to find suitable food sources when compared with birds living in high-quality habitats, i.e. in non-fragmented environments (Carey et al. 1990; Hansbauer et al. 2008). This might also be the case in the Arabuko Sokoke forest, where habitat quality is decreasing due to selective hardwood logging, charcoal production, and the removal of dead wood (Glenday 2005; Virani et al. 2010; Matiku et al. 2013).

In addition to anthropogenic activities, changes in the density of mega-herbivores such as elephants can also impact ecosystem structure (Villard et al. 1999; Ndang'ang'a et al. 2013; Banks et al. 2012, 2017), species composition and populations of single taxa (Fanshawe 1995; Clergeau and Burel 1997; Barros and Cintra 2009). Previous studies have shown that elephants increase the accumulation of dead wood and the availability of elephant dung, leading to a rise in insect activity and changes to arthropod community composition which then affects higher trophic levels, such as birds (Otieno et al. 2014). In addition, elephants may destroy large trees, which provide important breeding sites to $O$. ireneae.

\section{Indicator and flagship species}

Our SDMs indicated that tree height (availability of large old trees), NDVI (biomass), and vegetation type (Cynometra woodland) are the strongest explanatory variables for predicting $O$. ireneae occurrence within the Arabuko Sokoke forest. The SDM demonstrated the restriction of $O$. ireneae to the Cynometra woodland forest type, a finding in line with the study by Virani (1994) on O. ireneae habitat demands in the Arabuko Sokoke forest. Our data further indicated several roosting places per owl, always located in the centre of the AKDE50 area. Owls return to these roosting places after nocturnal foraging, using different roosting places in an alternating manner. All roosting places were characterised by high Cynometra trees and were covered by dense lianas and vines (Camilo Zamora \& Ivon Cuadros-Casanova, personal observations). This again underlines the importance of undisturbed Cynometra woodland to this sensitive bird species.

Our SDMs reveal that $O$. ireneae is neither homogeneously distributed across Arabuko Sokoke forest, nor homogeneously distributed across Cynometra woodland (a fraction of Arabuko Sokoke forest; Fig. 2). The only suitable habitat in the Arabuko Sokoke forest is Cynometra woodland with dense vegetation and large, old trees and a high proportion of deadwood. Decreasing habitat quality may reduce the carrying capacity of $O$. ireneae, and may also negatively impact other forest specialist species. With a mean body weight of $50 \pm 1.7 \mathrm{~g}$, O. ireneae is the smallest owl of East Africa, and its colourful plumage makes it a very charismatic species. Along with being an indicator of intact Cynometra woodland forest, makes this owl an excellent flagship species to promote and conserve this endangered biodiversity hotspot. 
Acknowledgements Fieldwork was performed in collaboration with the Ornithology Section of the National Museums of Kenya, Nairobi, the Kenyan Forest Service, and the Kenyan Wildlife Service. We particularly thank David Ngala for his essential guidance in the field. This study was funded by the German Academic Exchange Service, in the framework of the Quality Network Biodiversity Kenya. We thank one anonymous referee for critical and fruitful comments on a previous version of this article, Martin Husemann (Hamburg, Germany) for a final read to improve the linguistic style and Jeremy Garnett of Top End Editing for copyediting.

Funding Open Access funding provided by Paris Lodron University of Salzburg.

Open Access This article is licensed under a Creative Commons Attribution 4.0 International License, which permits use, sharing, adaptation, distribution and reproduction in any medium or format, as long as you give appropriate credit to the original author(s) and the source, provide a link to the Creative Commons licence, and indicate if changes were made. The images or other third party material in this article are included in the article's Creative Commons licence, unless indicated otherwise in a credit line to the material. If material is not included in the article's Creative Commons licence and your intended use is not permitted by statutory regulation or exceeds the permitted use, you will need to obtain permission directly from the copyright holder. To view a copy of this licence, visit http://creativecommons.org/licenses/by/4.0/.

\section{References}

Achard F, Beuchle R, Mayaux P, Stibig HJ, Bodart C, Brink A, Donnay F, Lupi A, Carboni S, Desclee B, Donnay F, Eva HD, Lupi A, Rasi R, Seliher R, Simonetti D (2014) Determination of tropical deforestation rates and related carbon losses from 1990 to 2010. Global Change Biol 20:2540-2554

Aleman JC, Jarzyna MA, Staver AC (2018) Forest extent and deforestation in tropical Africa since 1900. Nat Ecol Evol 2:26

Banks JE, Jackson C, Baya A, Minella H, Nitz M, Hitchcock J, Bruinsma D (2012) Forest type preference of an Afrotropical thrush (East Coast Akalat, Sheppardia gunning sokokensis) in Arabuko-Sokoke Forest, Kenya. Ostrich 83:105-108

Banks JE, Stark JD, Vargas RI, Ackleh AS (2014) Deconstructing the surrogate species concept: a life history approach to the protection of ecosystem services. Ecol Appl 24:770-778

Banks JE, Jackson CHW, Gagic V, Baya AD, Ngala D (2017) Differential responses of bird species to habitat condition in a coastal Kenyan forest reserve: implications for conservation. Trop Conserv Sci 10:1-13

Barros OG, Cintra R (2009) The effects of forest structure on occurrence and abundance of three owl species (Aves: Strigidae) in the Central Amazon forest. Zoologia 26:85-96

Bennun LA, Njoroge P (1999) Important bird areas in Kenya. East Africa Natural History Society, Nature Kenya

Bennun L, Dranzoa C, Pomeroy D (1996) The forest birds of Kenya and Uganda. J East Afr Nat Hist 85:23-48

BirdLife International (2018) Otus ireneae., In: IUCN Red List of threatened species, version 2013.2. www. iucnredlist.org. Accessed 7 June 2018

Britton PL, Zimmerman DA (1979) The avifauna of Sokoke forest, Kenya. J East Afr Nat Hist 169:1-15

Calabrese JM, Fleming CH, Gurarie E (2016) CTMM: an r package for analyzing animal relocation data as a continuous-time stochastic process. Methods Ecol Evol 7:1124-1132

Calenge C (2006) The package adehabitat for the R software: a tool for the analysis of space and habitat use by animals. Ecol Model 197:516-519

Carey AB, Reid JA, Horton SP (1990) Spotted Owl home range and habitat use in Southern Oregon Coast Ranges. J Wildl Manag 54:11-17

Carignan V, Villard M-A (2002) Selecting indicator species to monitor ecological integrity: a review. Env Monitor Ass 78:45-61

Cincotta RP, Wisnewski J, Engelman R (2000) Human population in the biodiversity hotspots. Nature 404:990

Clergeau P, Burel F (1997) The role of spatio-temporal patch connectivity at the landscape level: an example in a bird distribution. Landsc Urban Plan 38:37-43

Collar NJ, Stuart SN (1988) Key forests for threatened birds in Africa. ICBP Monograph no. 3. International Council for Bird Preservation, Cambridge

Cuadros-Casanova I, Zamora C, Ulrich W, Seibold S, Habel JC (2018) Empty forests: safeguarding a sinking flagship in a biodiversity hotspot. Biodiv Conserv 27:2495-2506

Didan K, Munoz AB, Solano R, Huete A (2015) MODIS Vegetation Index User's Guide (MOD13Series) Version 3.00, Vegetation Index and PhenologyLab, University of Arizona

Evans TD (1997) Records of birds from the forests of the East Usambara lowlands, Tanzania. Scopus 19:92-108 
Fanshawe J (1995) The effect of selective logging on the bird community of the Arabuko-Sokoke Forest, Kenya. $\mathrm{PhD}$ thesis, University of Oxford, UK

Fleming CH, Calabrese JM (2017) A new kernel density estimator for accurate home-range and species-range area estimation. Methods Ecol Evol 8:571-579

Gatti RC, Castaldi S, Lindsell JA, Coomes DA, Marchetti M, Maesano M, Di Paola A, Paparella F, Valentini $R$ (2015) The impact of selective logging and clearcutting on forest structure, tree diversity and aboveground biomass of African tropical forests. Ecol Res 30:119-132

Geist HJ, Lambin EF (2002) Proximate causes and underlying driving forces of tropical deforestation: Tropical forests are disappearing as the result of many pressures, both local and regional, acting in various combinations in different geographical locations. Bio Sci 52:143-150

Githiru M, Lens L, Bennun LA, Matthysen E (2007) Can a common bird species be used as a surrogate to draw insights for the conservation of a rare species? A case study from the fragmented Taita Hills, Kenya. Oryx 41:239-246

Glenday J (2005) Preliminary assessment of carbon storage and the potential for forestry based carbon offset projects in the lower Tana river forests. Critical Ecosystems Partnership Fund

Gordon I, Ayiemba W (2003) Harnessing butterfly biodiversity for improving livelihoods and forest conservation: the Kipepeo project. J Env Dev 12:82-98

Habel JC, Cuadros Casanova IC, Zamora C, Teucher M, Hornetz B, Shauri H, Mulwa RK, Lens L (2017) East African coastal forest under pressure. Biodiv Conserv 26:2751-2758

Hansbauer MM, Storch I, Pimentel RG, Metzger JP (2008) Comparative range use by three Atlantic Forest understory bird species in relation to forest fragmentation. J Trop Ecol 24:291-299

Hansen MC, Potapov PV, Moore R, Hancher M, Turubanova SA, Tyukavina A, Thau D, Stehman SV, Goetz SJ, Loveland TR, Kommareddy A, Egorov A, Chini L, Justice CO, Townshend JRG (2013) High-resolution global maps of 21st-century forest cover change. Science 342:850-853

Hijmans RJ (2016) raster: Geographic Data Analysis and Modeling. R package version 2.5-8. https://CRAN.Rproject.org/package $=$ raster

Kelsey MG, Langton TE (1984) The conservation of the Arabuko-Sokoke forest, Kenya

Kenward R (2001) A manual for wildlife radio tagging. Acad Press, London

Matiku P, Caleb M, Callistus O (2013) The impact of participatory forest management on local community livelihoods in the Arabuko-Sokoke forest, Kenya. Conserv Soc 11:112

Maxwell SL, Fuller RA, Brooks TM, Watson JEM (2016) Biodiversity: the ravages of guns, nets and bulldozers. Nature 536:143

Miles L, Newton AC, DeFries RS, Ravilious C, May I, Blyth S, Kapos V, Gordon JE (2016) A global overview of the conservation status of tropical dry forests. J Biogeo 33:491-505

Muriithi S, Kenyon W (2002) Conservation of biodiversity in the Arabuko Sokoke Forest, Kenya. Biodiv Conserv 11:1437-1450

Murphy DM, Weiland PS, Cummins KW (2011) A critical assessment of the use of surrogate species in conservation planning in the Sacramento-San Joaquin delta, California (U.S.A.). Conserv Biol 25:873-878

Ndang' ang'a PK, Njoroge JBM, Githiru M (2013) Vegetation composition and structure influences bird species community assemblages in the highland agricultural landscape of Nyandarua, Kenya. Ostrich 84:171-179

Noonan MJ et al (2019) A comprehensive analysis of autocorrelation and bias in home range estimation. Ecol Monogr 89:e01344

Otieno NE, Ngala D, Mwalimu A (2014) Spatial response of the globally-endangered Sokoke Pipit (Anthius sokokensisvan van Someren, 1921) to habitat modification in an Eastern Arc Coastal Forest. F1000 Res 3:59

Phillips SJ, Anderson RP, Schapire RE (2006) Maximum entropy modelling of species geographic distributions. Ecol Model 190:231-259

Simard M, Pinto N, Fisher JB, Baccini A (2011) Mapping forest canopy height globally with spaceborne lidar. J Geophys Res 116

Simberloff D (1998) Flagships, umbrellas, and keystones: is single-species management passé in the landscape era? Biol Conserv 83:247-257

Villard MA, Trzcinski MK, Merriam R (1999) Fragmentation effects on forest birds: relative influence of woodland cover and configuration on landscape occupancy. Conserv Biol 13:774-783

Virani MZ (1994) Ecology of the endangered Sokoke Scops owl (Otus ireneae). University of Leicester, UK

Virani MZ (2000) Home range and movement patterns of Sokoke Scops Owl Otus ireneae. Ostrich 71:139-142

Virani MZ, Njoroge P, Gordon I (2010) Disconcerting trends in populations of the endangered Sokoke Scops Owl Otus ireneae in the Arabuko-Sokoke Forest, Kenya. Ostrich 81:155-158

Wass P (1995) Kenya's indigenous forests. IUCN, Gland, Switzerland, and Cambridge, UK in collaboration with ODA 
Wiktander U, Olsson O, Nilsson SG (2001) Seasonal variation in home-range size, and habitat area requirement of the Lesser Spotted Woodpecker (Dendrocopos minor) in southern Sweden. Bio Conserv 100:387-395

Publisher's Note Springer Nature remains neutral with regard to jurisdictional claims in published maps and institutional affiliations.

\section{Authors and Affiliations}

\section{Jan Christian Habel ${ }^{1,2}$ - Camilo Zamora ${ }^{2}$. Dennis Rödder ${ }^{3} \cdot$ Mike Teucher $^{4}$. Ivon Cuadros-Casanova ${ }^{2,5} \cdot$ Christina Fischer ${ }^{6,7}$}

1 Evolutionary Zoology, Department of Biosciences, University of Salzburg, Hellbrunner Str. 34, 5020 Salzburg, Austria

2 Terrestrial Ecology Research Group, Department of Ecology and Ecosystem Management, Technische Universität München, 85354 Freising, Germany

3 Zoologisches Forschungsmuseum Alexander Koenig, 53113 Bonn, Germany

4 Department of Geoecology, Institute of Geosciences and Geography, Martin-Luther-University of Halle-Wittenberg, 06099 Halle (Saale), Germany

5 Global Mammal Assessment Program, Department of Biology and Biotechnologies, Sapienza Università di Roma, Rome, Italy

6 Restoration Ecology, Department of Ecology and Ecosystem Management, Technische Universität München, 85354 Freising, Germany

7 Faunistics and Wildlife Conservation, Department Agriculture, Ecotrophology, and Landscape Development, Anhalt University of Applied Sciences, 06406 Bernburg, Germany 